\title{
High prevalence of epigenetic inactivation of the human four and a half LIM domains 1 gene in human oral cancer
}

\author{
KAZUYUKI KOIKE $^{1}$, ATSUSHI KASAMATSU ${ }^{1,2}$, MANABU IYODA ${ }^{1}$, YASUHIRO SAITO ${ }^{1}$, \\ YUKINAO KOUZU $^{1}$, HIROFUMI KOIKE ${ }^{1}$, YOSUKE SAKAMOTO ${ }^{2}$, KATSUNORI OGAWARA ${ }^{2}$, \\ HIDEKI TANZAWA $^{1,2}$ and KATSUHIRO UZAWA ${ }^{1,2}$ \\ ${ }^{1}$ Department of Clinical Molecular Biology, Graduate School of Medicine, \\ Chiba University; ${ }^{2}$ Department of Dentistry and Oral-Maxillofacial Surgery, \\ Chiba University Hospital, Chuo-ku, Chiba 260-8670, Japan
}

Received August 17, 2012; Accepted September 28, 2012

DOI: 10.3892/ijo.2012.1677

\begin{abstract}
The four and a half LIM domains 1 (FHLI) gene has been related to carcinogenesis. However, the expression status of FHL1 in human oral squamous cell carcinoma (OSCC) remains unclear and the detailed mechanism of gene silencing is poorly understood. The aim of this study was to examine the FHL1 expression level and its regulatory mechanism in OSCCs. Quantitative reverse-transcriptase-polymerase chain reaction (PCR) and western blotting showed significant downregulation of FHL1 in all OSCC-derived cell lines (Sa3, HSC-2, HSC-3, HSC-4, HO-1-u-1, HO-1-N-1, KON and Ca9-22) compared to human normal oral keratinocytes. We also found that FHL1 mRNA expression was frequently downregulated $(\mathrm{P}<0.01)$ in $51(86.4 \%)$ of 59 primary OSCCs compared with the corresponding normal oral tissues, while there was no significant difference between the status of the FHL1 protein expression in OSCCs and the clinicopathological features. Using methylationspecific PCR, we detected methylated FHL1 in all cell lines and treatment with the DNA methyltransferase inhibitor, 5-aza2'-deoxycytidine restored the FHL1 expression. However, no significant restoration of FHL1 expression was observed using sodium butyrate, an inhibitor of histone deacetylase and chromatin immunoprecipitation showed that histone H3 lysine 9 in the FHL1 promoter region was significantly acetylated. In addition, no mutation in the entire coding region of the FHLI gene was found. Therefore, our data suggested that inactivation of the FHL1 gene is a frequent event during oral carcinogenesis
\end{abstract}

Correspondence to: Dr Katsuhiro Uzawa, Department of Clinical Molecular Biology, Graduate School of Medicine, Chiba University, 1-8-1 Inohana, Chuo-ku, Chiba 260-8670, Japan

E-mail: uzawak@faculty.chiba-u.jp

Key words: oral squamous cell carcinoma, four and a half LIM domains 1 , quantitative reverse-transcriptase-polymerase chain reaction, western blotting, immunohistochemistry, 5-aza-2'-deoxycytidine, sodium butyrate, chromatin immunoprecipitation, methylation specific PCR and that the mechanism of FHL1 downregulation in OSCCs is through DNA methylation of the promoter region rather than histone deacetylation or mutation.

\section{Introduction}

Head and neck squamous cell carcinoma (HNSCC) is one of the most frequently occurring malignancies and a major cause of morbidity and mortality $(1,2)$. Oral cancer is the most common among the HNSCCs and the most frequently occurring oral cancer is squamous cell carcinoma (OSCC), which accounts for more than $90 \%$ of all oral malignancies (3). The number of OSCC cases that occur worldwide annually exceeds 300,000 (4). The mechanisms behind tumor progression of OSCC are known to a limited extent, indicating a clear need for comprehensive knowledge that can lead to more specific and effective molecular target

Microarray technology facilitates simultaneous evaluation of thousands of genes in a specimen. The results of microarray analysis provide researchers with high throughput screening to study the roles played by specific genes in cancer development and progression. We previously reported gene expression profiling of OSCC to identify cancer-related genes $(5,6)$.

The four and a half LIM domains (FHL) family of genes is characterized by LIM domains, a term derived from the first letters of three transcription factors: Lin-11, Isl-1 and Mec-3. Because the LIM domains provide protein-protein binding interfaces, the $F H L$ genes play an important role in cellular events such as focal adhesion and differentiation by repressing or activating target protein (7). FHL1 protein is highly expressed in skeletal muscle, where it localizes to sarcomeres and sarcolemmas (8) and is expressed at intermediate levels in cardiac muscle $(9,10)$. The molecules associated with intercellular adhesion might be inhibited during tumor progression (11). Accordingly, the expression of the $F H L$ family member $F H L 1$, located on human chromosome $\mathrm{Xq} 26$, was downregulated in various types of malignancies including lung, prostate and breast cancer (12).

Epigenetic alterations including hypermethylation of the promoter regions are consistent and early events in neoplastic progression. Such alterations are thought to contribute to the neoplastic process by transcriptional silencing of tumor suppressor 
gene expression. DNA methylation is reversible because it does not alter the DNA sequence; however, it is heritable from cell to cell (13). Epigenetic mechanisms have emerged recently as major determinants of gene expression and are implicated in the regulation of complex differentiation and developmental processes, both under physiologic and pathological conditions. In addition to hypermethylation of the promoter regions, histone modification, particularly histone acetylation, is a key factor in epigenetic regulation (14). Histone deacetylation, which is associated with a repressed chromatin state, is tightly controlled by two classes of enzymes, histone acetyltransferases and histone deacetylases (HDAC) (15). Inhibitors of HDAC display anti-cancer activities and are, therefore, of growing clinical interest (16).

In the present study, we showed that FHL1 is significantly downregulated in the OSCC-derived cell lines and tissue samples from patients with OSCC and the methylation status was significantly higher in OSCC specimens than in human normal oral keratinocyte (HNOK) specimens. Treatment with the DNA methyltransferase inhibitor, 5-aza-2'-deoxycytidine (5-aza-dC) restored FHL1 mRNA expression in the OSCCderived cell lines. In contrast, no significant restoration of FHL1 expression was observed when using sodium butyrate $(\mathrm{NaB})$, a histone deacetylase inhibitor and the FHL1 promoter region was significantly acetylated in the OSCC-derived cell lines. Direct sequencing did not detect any mutation in the entire coding region of the FHLl gene. These results suggested that downregulation of FHL1 expression in OSCC-derived cell lines and HNOKs is correlated with DNA hypermethylation of the FHL1 promoter region.

\section{Materials and methods}

Ethics statement. All patients provided informed consent after the study protocol was explained. The institutional review board of Chiba University approved the study.

OSCC-derived cell lines and tissue specimens. The HSC-3, HO-1-N-1 and KON cell lines, derived from human OSCCs, were purchased from the Human Science Research Resources Bank (Osaka, Japan). The RIKEN BRC provided the Sa3, HSC-2, HSC-4, HO-1-u-1 and Ca9-22 cell lines through the National Bio-Resource Project of the MEXT (Ibaraki, Japan). Short tandem repeat profiles confirmed cell identity. Primary cultured HNOKs were obtained from three healthy donors and served as the normal controls (17-21). All cells were grown in Dulbecco's modified Eagle's medium (Sigma, St. Louis, MO) supplemented with $10 \%$ fetal bovine serum (Sigma) and $50 \mathrm{U} / \mathrm{ml}$ penicillin and streptomycin (Sigma).

Tissue samples from 59 unrelated Japanese patients with primary OSCCs who were treated at the Chiba University Hospital were obtained during surgical resection. The resected tissues were divided into two parts, one of which was frozen immediately and stored at $-80^{\circ} \mathrm{C}$ until RNA isolation and the second was fixed in $20 \%$ buffered formaldehyde solution for pathologic diagnosis and immunohistochemistry (IHC). Histopathologic analysis of the tissues was performed according to the World Health Organization criteria by the Department of Pathology, Chiba University Hospital. Clinicopathologic staging was determined by the tumor-node-metastases classification of the International Union Against Cancer. All patients had OSCC that was confirmed histologically and tumor samples were checked to ensure that tumor tissue was present in $>90 \%$ of the specimen.

Preparation of $c D N A$. Total RNA was isolated using TRIzol Reagent (Invitrogen, Carlsbad, CA) according to the manufacturer's instructions. cDNA was generated from $5 \mu \mathrm{g}$ of total RNA using Ready-To-Go You-Prime First-Strand Beads (GE Healthcare, Buckinghamshire, UK) and oligo(dT) primer (Hokkaido System Science, Hokkaido, Japan), according to the manufacturer's instructions.

mRNA expression analysis. Quantitative reverse-transcriptasepolymerase chain reaction (qRT-PCR) was performed to evaluate the expression levels of the target gene $(F H L 1)$ in OSCC-derived cell lines using the Light Cycler ${ }^{\circledR}$ II 480 (Roche Diagnostics, Penzberg, Germany). The primer sequences used to analyze FHL1 mRNA expression were forward 5'-GAAGTGTGCTGGATG CAAGA-3' and reverse 5'-GGGGGCTTCCTAGCTTTAGA-3'. The PCR reactions were carried out in a final volume of $20 \mu \mathrm{l}$ of a reaction mixture comprised of $0.4 \mu \mathrm{l}(0.5 \mu \mathrm{M})$ of each primer, $0.2 \mu \mathrm{l}(0.2 \mu \mathrm{M})$ of universal probe (Roche Diagnostics), $4 \mu \mathrm{l}$ of PCR grade water, $10 \mu \mathrm{l}$ of $2 \mathrm{x}$ Probes Master (Roche Diagnostics) and $5 \mu \mathrm{l}$ of cDNA template according to the manufacturer's instructions. The qRT-PCR amplification was performed according to the following cycle parameters: an initial denaturation at $95^{\circ} \mathrm{C}$ for $5 \mathrm{~min}, 45$ cycles of amplification at $95^{\circ} \mathrm{C}(10 \mathrm{sec})$ for denaturation, $60^{\circ} \mathrm{C}(30 \mathrm{sec})$ for annealing and $72^{\circ} \mathrm{C}(1 \mathrm{sec})$ for extension. Following the amplification phase, a cooling step was performed at $50^{\circ} \mathrm{C}$ for $30 \mathrm{sec}$. The transcript amounts for the target genes were estimated from the respective standard curves and normalized to the glyceraldehyde-3-phosphate dehydrogenase (GAPDH) (forward 5'-GCTCTCTGCTCCTCCTGTTC-3' and reverse 5'-ACGACCAAATCCGTTGACTC-3') transcript amount determined in corresponding samples. All amplifications were repeated three times using cDNA prepared from three independent experiments.

Protein extraction. The cells were washed twice with cold phosphate-buffered saline (PBS) and centrifuged briefly. The cell pellets were incubated on ice for $30 \mathrm{~min}$ in a lysis buffer (7 M urea, $2 \mathrm{M}$ thiourea, 4\% w/v CHAPS and $10 \mathrm{mM}$ Tris $\mathrm{pH}$ 7.4) with a proteinase inhibitor cocktail (Roche Diagnostics). The protein concentration was measured with Bradford reagent (Bio-Rad, Richmond, CA).

Western blot analysis. Protein extracts were electrophoresed on $4-12 \%$ Bis-Tris gel, transferred to nitrocellulose membranes (Invitrogen) and blocked for $1 \mathrm{~h}$ at room temperature in Blocking One (Nacalai Tesque, Kyoto, Japan). The membranes were washed three times with $0.1 \%$ Tween-20 in Tris-buffered saline and incubated with $0.1 \mu \mathrm{g} / \mathrm{ml}$ rabbit anti-FHL1 polyclonal antibody (Aviva Systems Biology, San Diego, CA) overnight at $4^{\circ} \mathrm{C}$. The membranes were washed again and incubated with a 1:2,500 of anti-rabbit IgG $(\mathrm{H}+\mathrm{L})$ horseradish peroxidase (HRP) conjugate (Promega, Madison, WI) as a secondary antibody for $1 \mathrm{~h}$ at room temperature. The proteins were detected by SuperSignal Chemiluminescent substrate (Thermo, Waltham, MA). Finally, the western blot analysis results were visualized by exposing the membrane to a cooled CCD camera system, 
Light-Capture II (ATTO, Tokyo, Japan). Signal intensities were quantitated using the CS Analyzer version 3.0 software (ATTO).

IHC. IHC of 4- $\mu \mathrm{m}$ sections of paraffin-embedded specimens was performed using rabbit anti-FHL1 polyclonal antibody (Aviva Systems Biology). Briefly, after deparaffinization and hydration, the slides were pretreated in $10 \mathrm{mM}$ sodium citrate buffer (pH 6.0) in a microwave oven for $5 \mathrm{~min}$ at $95^{\circ} \mathrm{C}$. The endogenous peroxidase activity was quenched by a $30-\mathrm{min}$ incubation in a mixture of $0.3 \%$ hydrogen peroxide solution in $100 \%$ methanol, after which the specimens were blocked for $1 \mathrm{~h}$ at room temperature with $1.5 \%$ blocking serum (Santa Cruz Biotechnology, Santa Cruz, CA) in PBS before reaction with anti-FHL1 antibody $(4.0 \mu \mathrm{g} / \mathrm{ml})$ at $4^{\circ} \mathrm{C}$ in a moist chamber overnight. Upon incubation with the primary antibody, the specimens were washed three times in PBS and treated with Envision System-HRP Labeled Polymer (Dako, Carpinteria, CA) followed by color development in 3,3'-diaminobenzidine tetrahydrochloride (Dako). The slides were then lightly counterstained with hematoxylin, dehydrated with ethanol, cleaned with xylene and mounted. To quantify the state of FHL1 protein expression in those components, we used IHC score systems described previously (18,22-30). Briefly, the stained cells were determined in at least five random fields at magnification $x 400$ in each section. The intensity of the FHL1 immunoreaction in the cells was scored as follows: 1+, weak; $2+$, moderate; and $3+$, intense. The cell number and the staining intensity then were multiplied to produce an FHL1 IHC score. Cases with a score exceeding 36.5 ( \pm 3 standard deviation) (SD) score for normal tissue) were defined as FHL1-positive. The \pm 3 SD cutoff, which statistically is $0.2 \%$ of the measurement and is expected to fall outside this range, was used because it was unlikely to be affected by a random experimental error produced by sample manipulation (31). Two independent pathologists, both of whom were masked to the patients' clinical status, made these judgments.

Cell culture and 5-aza-2'-deoxycytidine treatment. To assess reactivation of $F H L 1$ gene expression, OSCC derived cell lines were treated with different concentrations $(0$ and $2 \mu \mathrm{M})$ of the DNA methyltransferase inhibitor, 5-aza-dC (Wako, Osaka, Japan). On day 7, the cells were harvested, total RNA was extracted and qRT-PCR was performed (19).

Methylation-specific PCR. To determine if methylation of a $\mathrm{CpG}$ island of the FHL1 promoter region contributes to the mRNA expression of FHL1, DNA samples obtained from OSCCderived cell lines were applied for the methylation-specific PCR (MSP) assay. Bisulfite conversion was carried out using the EZ DNA Methylation Direct kit (Zymo Research, Orange, CA) according to the manufacturer's instructions with the following modifications. Briefly, $1 \times 10^{5}$ cells of genomic DNA was denatured by the addition of digestion mixture, which contained $13 \mu \mathrm{l}$ of M-Digestion Buffer (Zymo Research), $6 \mu$ l PCR grade water and $1 \mu \mathrm{l}$ Proteinase $\mathrm{K}$ (Zymo Research). After incubation at $50^{\circ} \mathrm{C}$ for $20 \mathrm{~min}$, the $20 \mu \mathrm{l}$ sample was added to $130 \mu \mathrm{l}$ of CT Conversion Reagent (Zymo Research) in a PCR tube. The tubes were placed in the thermal cycler (Applied Biosystems, Foster City, CA) for $8 \mathrm{~min}$ at $98^{\circ} \mathrm{C}$ for DNA denaturation and $3.5 \mathrm{~h}$ at $64^{\circ} \mathrm{C}$ for bisulfite conversion. The modified DNA then was desalted, purified using Zymo-Spin IC Column (Zymo Research) and eluted with $10 \mu$ l elution buffer. Bisulfite modified DNA was used as a template and then MSP was performed. The primers for MSP were designed using MethPrimer software (http:// www.urogene.org/methprimer) (32). The primer sequences were: FHL1 methylated forward, 5'-GTAAGTTATCGGGTTT CGAAGTC-3'; FHL1 methylated reverse, 5'-ACAACCAAATA AAAATAACGTCTCG-3'; FHL1 unmethylated forward, 5'-TGTAAGTTATTGGGTTTTGAAGTTG-3'; and FHL1 unmethylated reverse 5'-AACCAAATAAAAATAACATCTC ACC-3'. The PCR reactions were performed in a final volume of $25 \mu \mathrm{l}$ containing $50 \mathrm{ng}$ of digested DNA, $0.3 \mu \mathrm{M}$ of each specific primer, $0.25 \mu \mathrm{l}$ of $100 \mathrm{X} \mathrm{SYBR}^{\circledR}$ Green I and $0.6 \mu \mathrm{l}$ of MSP Enzyme (Takara Bio, Shiga, Japan). PCR amplification was carried out at $95^{\circ} \mathrm{C}$ for $30 \mathrm{sec}, 40$ cycles at $98^{\circ} \mathrm{C}$ for $5 \mathrm{sec}$, $55^{\circ} \mathrm{C}$ for $30 \mathrm{sec}$ and $72^{\circ} \mathrm{C}$ for $1 \mathrm{~min}$. The amplified PCR products were separated on $10 \%$ polyacrylamide gel and visualized by ethidium bromide after the run. EpiScope ${ }^{\circledR}$ Methylated HeLa Genomic DNA (Takara Bio) was used as a positive control for methylated alleles. HNOKs genomic DNA was used as a negative control for unmethylated genes $(19,33)$.

Treatment with HDAC inhibitor and chromatin immunoprecipitation. OSCC-derived cells were treated with a $\mathrm{NaB}$, an HDAC inhibitor, $\mathrm{NaB}$ (Wako). All OSCC-derived cell lines were plated at $50 \%$ confluence and treated with $5.0 \mathrm{mM}$ of $\mathrm{NaB}$. After a 24-h incubation, total RNA was isolated from OSCC-derived cell lines and qRT-PCR was performed.

Chromatin immunoprecipitation (ChIP) assays for histone acetylation and histone methylation were performed using an EpiScope ChIP Kit (anti-mouse IgG) (Takara Bio) according to the manufacturer's instructions. The OSCC-derived cell lines $\left(5 \times 10^{6}\right.$ cells in a $10-\mathrm{cm}$ dish) were cross-linked with $10 \mathrm{ml}$ of $1 \%$ formaldehyde in medium for $5 \mathrm{~min}$ at room temperature and then incubated in $2.1 \mathrm{ml}$ Quenching Solution (Takara Bio) in medium for $5 \mathrm{~min}$. After rinsing cells with PBS, $1 \mathrm{ml}$ of PBS was added to harvest cells using a cell scraper. The cells were collected by centrifugation $\left(180 \mathrm{~g}, 3 \mathrm{~min}, 4^{\circ} \mathrm{C}\right)$ and resuspended in $1 \mathrm{ml}$ Cytoplasmic Lysis Buffer (Takara Bio) sheared with a Biomic 7040 Ultrasonic Processor (Seiko, Tokyo, Japan) to obtain 200-1,000-bp fragments. After centrifugation $(15,000 \mathrm{~g}, 3 \mathrm{~min}$, $4^{\circ} \mathrm{C}$ ) to remove insoluble materials, $600 \mu \mathrm{l}$ of dilution buffer (Takara Bio) was added to the supernatant. For cross-linked ChIP, $200 \mu \mathrm{l}$ of Magnosphere ${ }^{\mathrm{TM}}$ anti-mouse IgG (Takara Bio) was washed with RIPA Buffer-1 (Takara Bio), incubated with antiacetyl histone $\mathrm{H} 3$ lysine 9 (4 $\mu \mathrm{g})$ (H3K9ac), mouse monoclonal antibody (MAB Institute, Hokkaido, Japan), anti-monomethyl histone $\mathrm{H} 3$ lysine 9 (4 $\mu \mathrm{g})$ (H3K9me), mouse monoclonal antibody (MAB Institute), or control antibody ( $4 \mu \mathrm{g}$ ) (normal goat IgG, Santa Cruz) in a $2-\mu 1$ proteinase inhibitor cocktail (Takara Bio), $20 \mu 1$ 10X EASY Dilution (Takara Bio) and $54 \mu$ l RIPA Buffer-1 overnight at $4^{\circ} \mathrm{C}$ with rotation. After two washings with $800 \mu$ l RIPA Buffer-1, an aliquot of ChIP input (10 $\mu \mathrm{l})$ was incubated with Magnosphere anti-mouse IgG overnight at $4^{\circ} \mathrm{C}$ with rotation. The beads were washed sequentially with $800 \mu \mathrm{l}$ of RIPA Buffer-1, $800 \mu$ l of RIPA Buffer- 2 and $800 \mu$ l of TE (Takara Bio) handled with a magnetic stand (Takara Bio). After removing the TE, the beads were mixed with $100 \mu$ l chelate resin and incubated for $15 \mathrm{~min}$ at $95^{\circ} \mathrm{C}$ to reverse cross-linking. The samples were treated with $1 \mu \mathrm{l}$ Proteinase $\mathrm{K}$ and $1 \mu \mathrm{l}$ RNase A (Takara Bio) and incubated for $15 \mathrm{~min}$ at $65^{\circ} \mathrm{C}$ and boiled at $95^{\circ} \mathrm{C}$ 
Table I. Primers used in mutation analysis.

\begin{tabular}{llll}
\hline Exons & \multicolumn{1}{c}{ Forward primer } & \multicolumn{1}{c}{ Reverse primer } & Size (bp) \\
\hline Exon 2 & 5'-ATGAGGGAGCCAGATCCAC-3' & 5'-AGACATTGCCCCCGAGAG-3' & 486 \\
Exon 3 & 5'-GTCCTCAGACCCCATGGAC-3' & 5'-CTCAAGGTGGCTGCAGTG-3' & 415 \\
Exon 4 & 5'-CCCAGGTGTAAGGGACTGTG-3' & 5'-ACGTTAGCCCCACCATGA-3' & 387 \\
Exon 5 & 5'-CATCCCCTCACCTCTGGA-3' & 5'-TACGTCACAGGGCTGTCGT-3' & 382 \\
Exon 6 & 5'-CCCATGGCTGTTGTGGAG-3' & 5'-CAATAGCAGGGGGAGAAGG-3' & 441 \\
Exon 7-1 & 5'-GCTTGTCGGTCTGTGAGTGG-3' & 5'-ACTTTGCTGCAGGGTTGC-3' & 484 \\
Exon 7-2 & 5'-AGGGGAAGAGTGGTCCTTCC-3' & 5'-AGGGCAGAGTTCTGATGAGG-3' & 426 \\
\hline
\end{tabular}

for $10 \mathrm{~min}$ to deactivate the proteinase $\mathrm{K}$. After centrifugation $\left(15,000 \mathrm{~g}, 1 \mathrm{~min}, 4^{\circ} \mathrm{C}\right)$ the supernatant was collected. Each sample was analyzed by qRT-PCR and the results were expressed as percentages of the input DNA. The primer sequences were FHL1 promoter forward: 5'-TACTAAGGGGAGGGGTCGTC-3' and FHL1 promoter reverse: 5'-GAGGTGGGAGCAACAAAGAC-3' $(34,35)$.

Mutation analysis. To screen the sequence variations of the FHLI gene, direct DNA sequencing was performed as described previously (10). Fragments encompassing each of the six coding exons (exons 2-7) of FHL1 and their corresponding splice junctions were amplified (primer sequences in Table I). Amplifications were performed with FastStart Taq polymerase as described. Sequencing reactions were carried out using BigDye V3.1 Cycle Sequencing kit (Applied Biosystems) with the same forward primers as for PCR amplification and sequencing products were electrophoresed on an ABI PRISM 3130xl Genetic Analyzer (Applied Biosystems). PCR amplification was carried out with an ABI 7500 Real-Time PCR system (Applied Biosystems) under the following conditions: an initial denaturation step at $95^{\circ} \mathrm{C}$ for $10 \mathrm{~min}, 40$ cycles of $95^{\circ} \mathrm{C}$ for $15 \mathrm{sec}$ and $60^{\circ} \mathrm{C}$ for $1 \mathrm{~min}$ and a final extension for $1 \mathrm{~min}$.

Statistical analysis. The statistical significance of the FHL1 expression levels was evaluated using Fisher's exact test or Mann-Whitney $\mathrm{U}$ test. $\mathrm{P}<0.05$ was considered statistically significant. The data are expressed as the mean \pm standard error of the mean.

\section{Results}

Evaluation of FHL1 $\mathrm{mRNA}$ and protein expression in OSCCderived cell lines. To investigate $\mathrm{mRNA}$ and protein expression of FHL1 identified as a cancer-related gene in our previous microarray data (6), we performed qRT-PCR and western blot analyses using eight OSCC-derived cell lines (Sa3, HSC-2, HSC-3, HSC-4, HO-1-u-1, HO-1-N-1, KON and Ca9-22). FHL1 mRNA was significantly (Fig. $1,{ }^{*} \mathrm{P}<0.01$ ) downregulated in all OSCC-derived cell lines compared to the HNOKs. Representative results of the western blot analysis are shown in Fig. 1. The molecular weight of the FHL1 was $32 \mathrm{kDa}$. Mouse skeletal muscle lysate was used as a positive control. A significant decrease in FHL1 protein expression was observed in all OSCC-derived cell lines compared to the HNOKs.
A

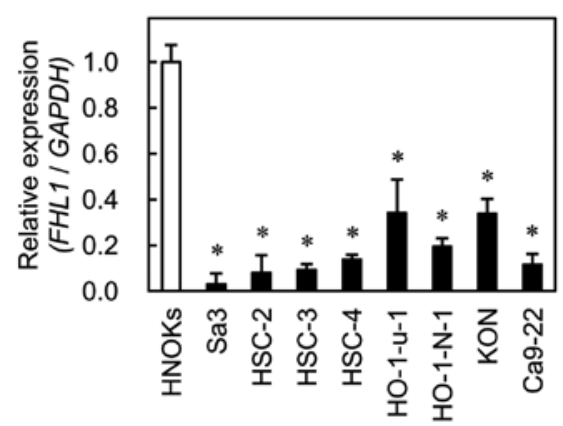

B

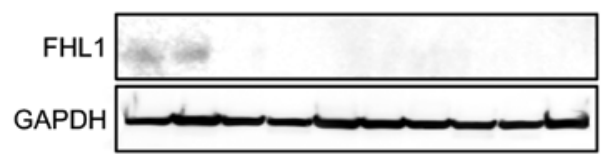

Figure 1. Quantification of FHL1 mRNA levels in OSCC-derived cell lines by qRT-PCR analysis (A). To determine mRNA expression of FHL1 in OSCC, we performed qRT-PCR analysis using eight OSCC-derived cell lines ( $\mathrm{Sa} 3$, HSC-2, HSC-3, HSC-4, Ca9-22, HO-1-u-1, HO-1-N-1 and Ca9-22) and HNOKs. Significant downregulation of FHL1 mRNA is seen in all OSCC-derived cell lines compared with that in the HNOKs. Data are expressed as the means \pm standard errors of the mean of values from three assays ( $\mathrm{P}<0.01$, Mann-Whitney $\mathrm{U}$ test). To investigate protein expression of FHL1 in OSCC, we performed western blot analysis using eight OSCC-derived cell lines (Sa3, HSC-2, HSC-3, HSC-4, HO-1-u-1, HO-1-N-1, KON and Ca9-22) and HNOKs (B).

Evaluation of FHL1 expression in primary OSCCs. We measured the FHL1 mRNA expression levels in primary OSCCs and paired normal oral tissues from 59 patients. Similar to the data from the OSCC-derived cell lines, qRT-PCR analysis showed that FHL1 mRNA expression was downregulated in 51 of $59(86.4 \%)$ primary OSCCs compared to the corresponding normal oral tissues (Fig. 2). The relative mRNA levels in the normal oral tissues and primary OSCCs ranged from 0.61 to 32.24 (median 8.02) and 0.09 to 7.81 (median 1.49), respectively $(\mathrm{P}<0.01)$. We analyzed FHL1 protein expression in primary OSCCs using the IHC scoring system. The FHL1 IHC scores of normal oral tissues and OSCCs ranged from 36.5 to 260.8 (median 160.0) and 35.0 to 181.5 (median 45.0), respectively. The IHC scores in primary OSCCs were significantly $(\mathrm{P}<0.01)$ lower than in normal oral tissues (Fig. 2). Representative IHC results for FHL1 protein in normal oral tissue and primary 
A

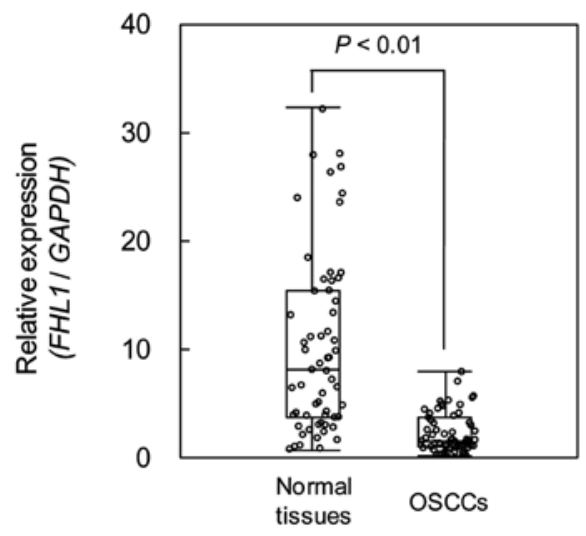

B

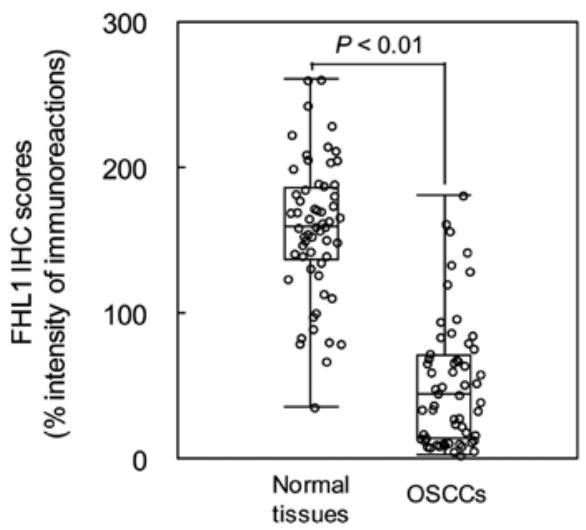

Figure 2. Comparison of FHL1 mRNA expression levels between primary OSCCs and matched normal oral tissues in clinical specimens (A). To investigate the FHL1 mRNA expression levels in primary OSCCs and paired normal oral tissues from 59 patients, we performed qRT-PCR analysis. The relative mRNA expression levels in primary OSCCs and the matched oral tissues $(n=59)$ range from 0.09 to 7.81 (median 1.49) and 0.16 to 32.24 (median 8.02), respectively. FHL1 mRNA expression is downregulated in 51 (86.4\%) of 59 primary OSCCs compared with the matched normal oral tissues. Significantly lower FHL1 mRNA expression is observed in primary OSCCs compared with matched normal oral tissues $(\mathrm{P}<0.01$, Mann-Whitney U test). The FHL1 IHC scores of the normal oral tissues and OSCCs range from 36.5 to 260.8 (median 160.0) and 35.0 to 181.5 (median 45.0), respectively (B). The IHC scores in primary OSCCs are significantly $(\mathrm{P}<0.01$, Mann-Whitney $\mathrm{U}$ test $)$ lower than in normal oral tissues.
OSCCs are shown in Fig. 3. Strong FHL1 immunoreactivity was detected in the cytoplasm of the basal cell layers in normal tissue, whereas the OSCCs showed almost negative immunostaining. The correlations between the clinicopathologic characteristics of the patients with OSCC and the status of the FHL1 protein expression level are shown in Table II. There was no significant difference between the frequency of FHL1-negative cases and clinicopathologic features.

Methylation analysis. To investigate the mechanisms responsible for downregulation of FHL1 expression, we analyzed the methylation status of the FHL1 promoter region in the OSCCderived cell lines. FHL1 promoter methylation was detected in all cell lines (Fig. 4). To further study the consequences of loss of expression of FHL1 in association with hypermethylation at the promoter region, the OSCC-derived cell lines, which showed methylation and transcriptional inactivation of FHL1, were treated with 5-aza-dC. Significantly $(\mathrm{P}<0.02)$ upregulated expression of the FHL1 gene was observed after 5-aza-dC treatment in all eight cell lines (Fig. 5).

Effects of $\mathrm{NaB}$ on FHL1 expression. OSCC-derived cells were treated with $\mathrm{NaB}$ to assess the effects of an HDAC inhibitor on FHL1 expression. In the Sa3, HSC-2 and HO-1-N-1 cell lines, FHL1 was significantly $(\mathrm{P}<0.05)$ upregulated after treatment with $\mathrm{NaB}$ for $24 \mathrm{~h}$ compared to the untreated cells. There were no significant changes in the other cell lines (Fig. 6).

Histone 3 modification in OSCC cell lines. Because FHL1 hypermethylation was detected in OSCC-derived cell lines, we examined histone modification as another mechanism responsible to FHL1 silencing in OSCCs. We conducted ChIP of acetyl histone $\mathrm{H} 3$ at lysine 9 (H3K9ac) and monomethyl histone $\mathrm{H} 3$ at lysine 9 (H3K9me) in all cell lines and found significant enrichment of $\mathrm{H} 3 \mathrm{~K} 9 \mathrm{ac}$ and $\mathrm{H} 3 \mathrm{~K} 9 \mathrm{me}$ at the promoter region of FHL1 in OSCC-derived cell lines (Fig. 7).

Mutational analysis. We screened DNA samples obtained from HNOKs and eight OSCC-derived cell lines by direct sequencing. No band shifting was detected in any exons of the FHL1 gene.
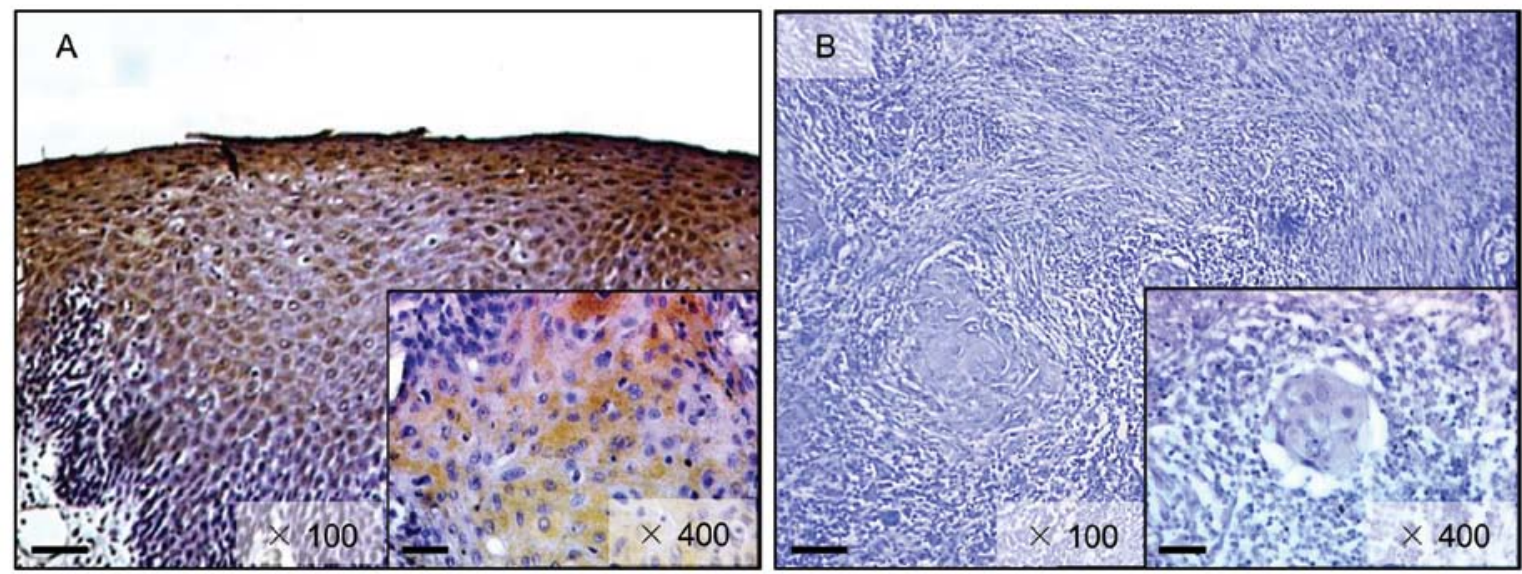

Figure 3. Evaluation of FHL1 protein expression in primary OSCCs. Representative IHC results of FHL1 protein in normal oral tissue (A) and primary OSCC (B) (original magnification $\mathrm{x} 100$. Scale bars, $100 \mu \mathrm{m}$. Inset, original magnification $\mathrm{x} 400$. Scale bars, $20 \mu \mathrm{m}$ ). Strong FHL1 immunoreactivity is detected in the cytoplasm in normal tissue, whereas the OSCCs show almost negative immunostaining. 
Table II. Correlation between the expression of FHL1 and clinical classification in OSCCs.

\begin{tabular}{|c|c|c|c|c|}
\hline \multirow[b]{2}{*}{ Clinical classification } & \multirow[b]{2}{*}{ Total } & \multicolumn{2}{|c|}{$\begin{array}{l}\text { Results of immunostaining } \\
\text { No. of patients (\%) }\end{array}$} & \multirow[b]{2}{*}{ P-value } \\
\hline & & FHL1(-) & FHL1(+) & \\
\hline \multicolumn{5}{|l|}{ Age at surgery (years) } \\
\hline$<60$ & 16 & $8(13.6)$ & $8(13.6)$ & \multirow[t]{3}{*}{0.615} \\
\hline $60-70$ & 13 & $8(13.6)$ & $5(8.5)$ & \\
\hline$>70$ & 30 & $16(27.1)$ & $14(23.7)$ & \\
\hline \multicolumn{5}{|l|}{ Gender } \\
\hline Male & 40 & $19(32.2)$ & $21(35.6)$ & \multirow[t]{2}{*}{0.168} \\
\hline Female & 19 & $13(22.0)$ & $6(10.2)$ & \\
\hline \multicolumn{5}{|l|}{ T-primary tumor size } \\
\hline $\mathrm{T} 1$ & 4 & $\begin{array}{ll}0 & (0.0)\end{array}$ & $4(6.8)$ & \multirow[t]{6}{*}{0.366} \\
\hline $\mathrm{T} 2$ & 35 & $18(30.5)$ & $17(28.8)$ & \\
\hline $\mathrm{T} 3$ & 7 & $6(10.2)$ & $1(1.7)$ & \\
\hline $\mathrm{T} 4$ & 13 & $8(13.6)$ & $5(8.5)$ & \\
\hline $\mathrm{T} 1+\mathrm{T} 2$ & 39 & $18(30.5)$ & $21(35.6)$ & \\
\hline $\mathrm{T} 3+\mathrm{T} 4$ & 20 & $14(23.7)$ & $6(10.2)$ & \\
\hline \multirow{2}{*}{\multicolumn{5}{|c|}{$\begin{array}{l}\text { N-regional lymph } \\
\text { node metastasis }\end{array}$}} \\
\hline & & & & \\
\hline $\mathrm{N}(+)$ & 22 & $12(20.3)$ & 10 (16.9) & \multirow[t]{2}{*}{0.593} \\
\hline $\mathrm{N}(-)$ & 37 & $20(33.9)$ & $17(28.8)$ & \\
\hline \multicolumn{5}{|l|}{ Stage } \\
\hline I & 3 & $0 \quad(0.0)$ & $3(5.1)$ & \multirow[t]{6}{*}{0.259} \\
\hline II & 22 & $13(22.0)$ & $9(15.3)$ & \\
\hline III & 8 & $5 \quad(8.5)$ & $3(5.1)$ & \\
\hline IV & 26 & $14(23.7)$ & $12(20.3)$ & \\
\hline $\mathrm{I}+\mathrm{II}$ & 25 & $13(22.0)$ & $12(20.3)$ & \\
\hline $\mathrm{III}+\mathrm{IV}$ & 34 & $19(32.2)$ & $15(25.4)$ & \\
\hline \multicolumn{5}{|l|}{ Histopathological type } \\
\hline Well differentiated & 38 & $19(32.2)$ & $19(32.2)$ & \multirow[t]{3}{*}{0.137} \\
\hline Moderately differentiated & 17 & $10(16.9)$ & $7(11.9)$ & \\
\hline Poorly differentiated & 4 & $3(5.1)$ & $1(1.7)$ & \\
\hline \multicolumn{5}{|l|}{ Tumor site } \\
\hline Tongue & 32 & $14(23.7)$ & $18(30.5)$ & \multirow[t]{5}{*}{0.327} \\
\hline Gingiva & 17 & $12(20.3)$ & $5(8.5)$ & \\
\hline Buccal mucosa & 4 & $2(3.4)$ & $2(3.4)$ & \\
\hline Palate & 3 & $3(5.1)$ & $\begin{array}{ll}0 & (0.0)\end{array}$ & \\
\hline Oral floor & 3 & 1 (1.7) & $2(3.4)$ & \\
\hline Total & 59 & 32 & 27 & \\
\hline
\end{tabular}

\section{Discussion}

We found that FHL1 was significantly downregulated at the mRNA and protein level in the human OSCC-derived cell lines and primary OSCCs. Treatment with DNA methyltransferase inhibitor 5-aza-dC restored FHL1 expression in all OSCC-derived cell lines. The promoter region of FHL1 DNA methylation also was detected in these cell lines. In contrast, 
$\mathrm{Sa} 3$

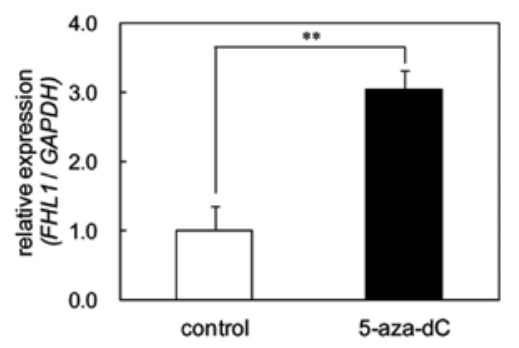

HSC-3

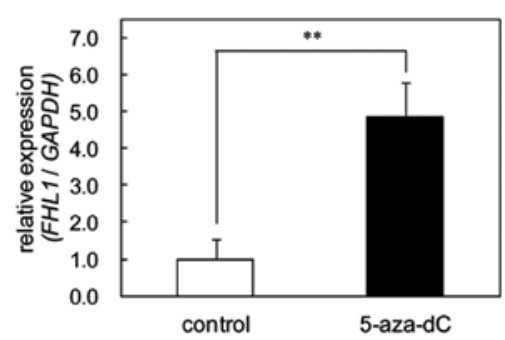

HO-1-u-1

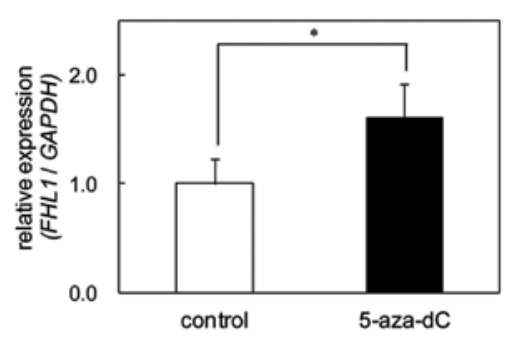

KON

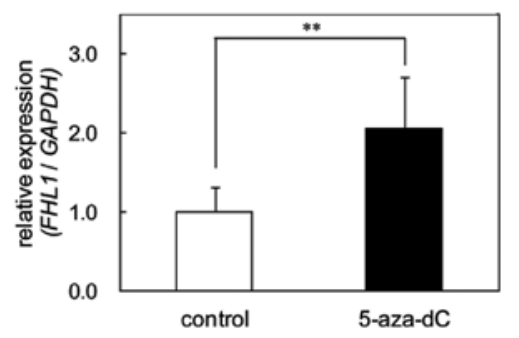

HSC-2

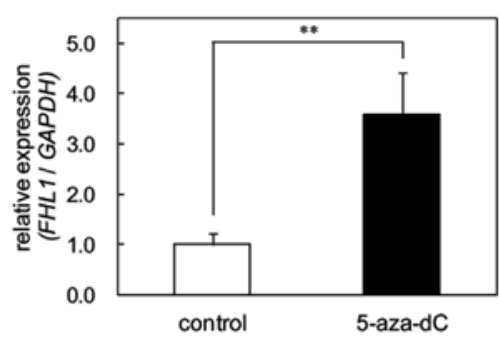

HSC-4

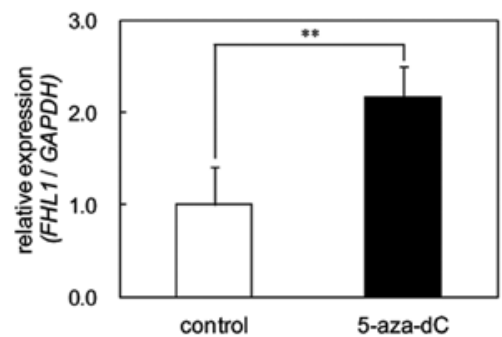

$\mathrm{HO}-1-\mathrm{N}-1$

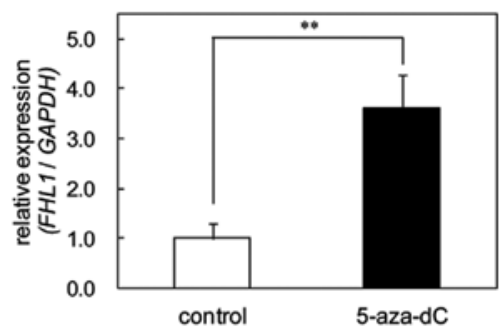

Ca9-22

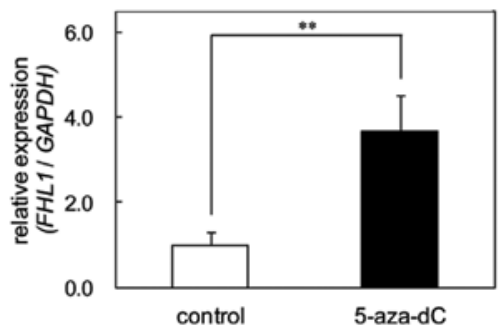

Figure 4. qRT-PCR for demethylation assay in OSCC-derived cell lines. Upregulation of $F H L 1$ mRNA expression is seen in all OSCC-derived cell lines after 5-aza-dC treatment $\left({ }^{*} \mathrm{P}<0.05,{ }^{* *} \mathrm{P}<0.01\right.$, Mann-Whitney U test).

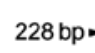

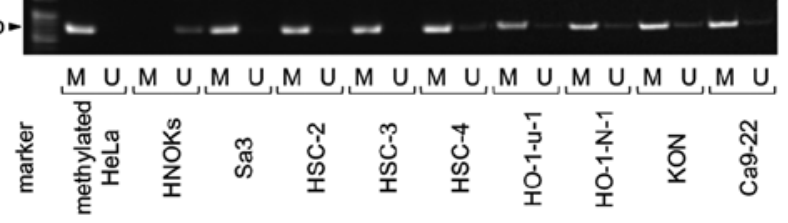

Figure 5. MSP analysis using specific primers for the FHL1 gene show that FHL1 methylation is detected in all cell lines. Primer sets used for amplification are designated as methylated (M) or unmethylated (U). Methylated HeLa genomic DNA is used as a positive control for methylated alleles; HNOK genomic DNA is used as a negative control for methylated genes. no significant restoration of FHL1 expression was observed using $\mathrm{NaB}$, an inhibitor of histone deacetylase and the FHL1 promoter region was significantly acetylated in all cell lines. Direct sequencing did not show any mutation in the entire coding region of the $F H L 1$ gene. In contrast to mutational analyses, qRT-PCR analysis of FHL1 mRNA showed frequent gene downregulation, indicating that other mechanisms, such as DNA methylation and histone deacetylation, are related to FHL1 gene silencing.

Although FHL1 downregulation has been reported in several cancers, i.e., lung, breast and bladder (36-38), the expression 
$\mathrm{Sa} 3$

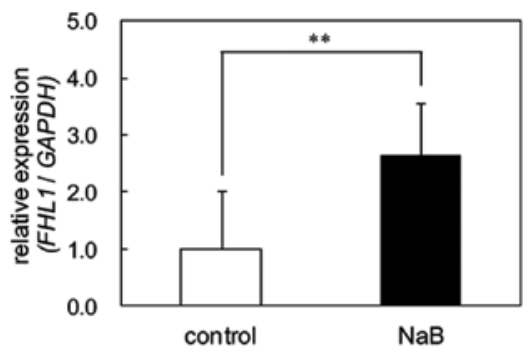

HSC-3

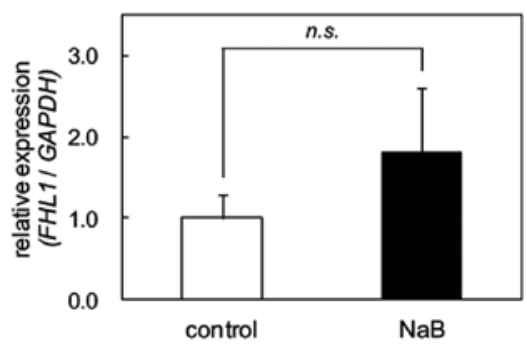

HO-1-u-1

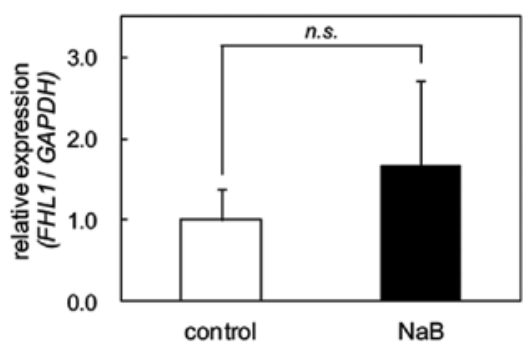

KON

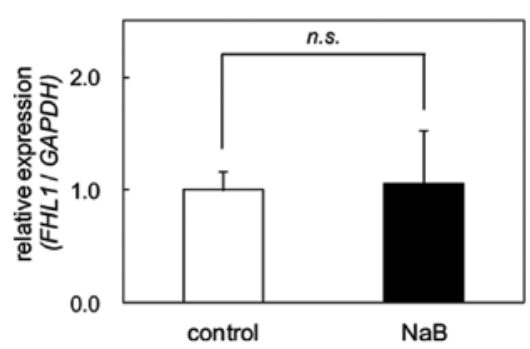

HSC-2

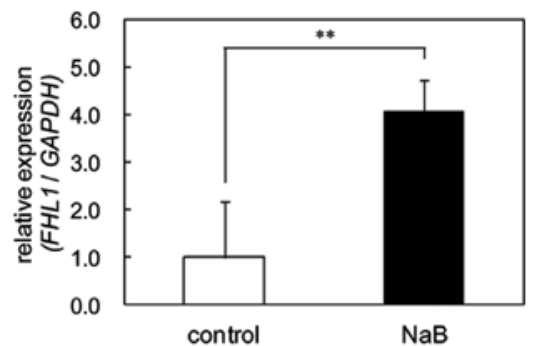

HSC-4

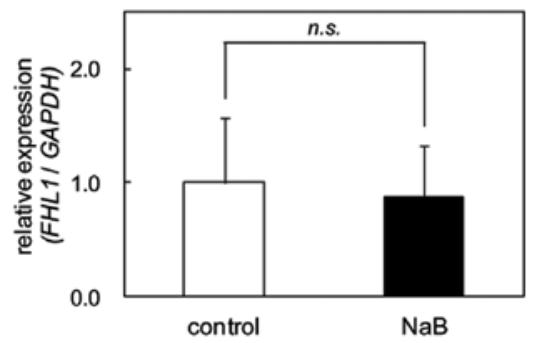

$\mathrm{HO}-1-\mathrm{N}-1$

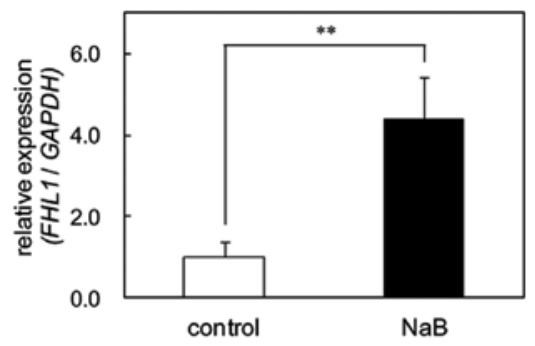

Ca9-22

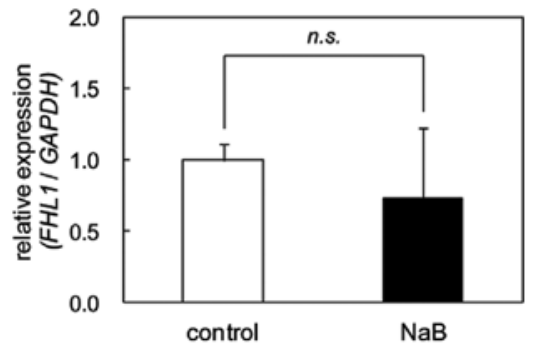

Figure 6. The effect of NaB on FHL1 mRNA expression in OSCC-derived cell lines. Cells were treated with $5.0 \mathrm{mM} \mathrm{NaB}$ for $24 \mathrm{~h}$. FHL1 mRNA levels are restored in NaB-treated cells compared to untreated cells ( $\mathrm{P}<0.01$, Mann-Whitney $\mathrm{U}$ test).

level and molecular function of FHL1 in OSCCs have not been clarified. Since many tumor suppressor genes silenced by DNA methylation have been identified in primary OSCC tissue samples, we hypothesized that FHL1 expression is downregulated by promoter hypermethylation and that FHL1 functions as a tumor suppressor in OSCC-derived cell lines.

Hypermethylation of the promoter regions of various genes has been recognized as one of the most frequent mechanisms causing loss of gene function. Several studies have reported an association between aberrant DNA methylation and carcinogenesis (39-41). However, the association between epigenetic changes and cancer etiology needs to be elucidated.

Several studies have reported a link between DNA methylation and histone acetylation in which a family of methyl-CpG-binding proteins is involved (42). Chromatin modifications are one of the molecular mechanisms that mediate epigenetic regulation (43). Of them, HDACs, the chromatin-modifying enzymes, remove the acetyl groups, leading to chromatin condensation and repres- 
Sa3

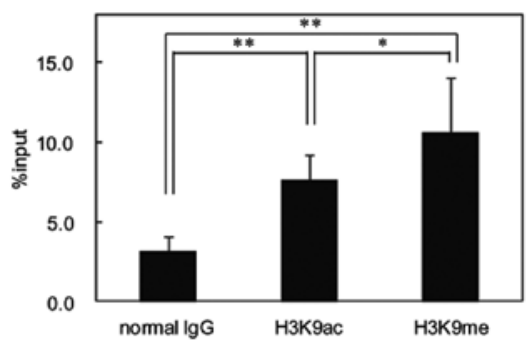

HSC-3

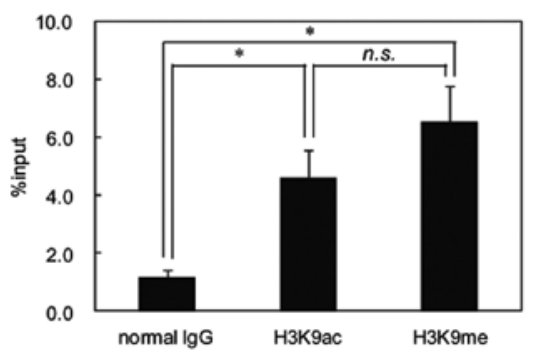

HO-1-u-1

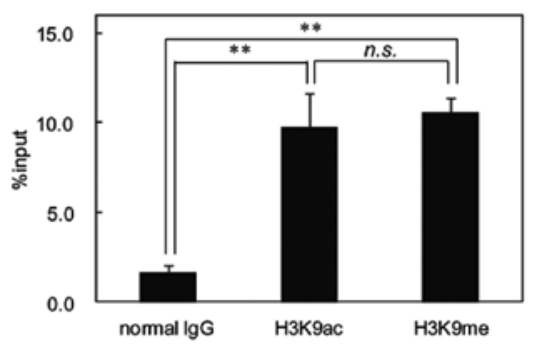

KON

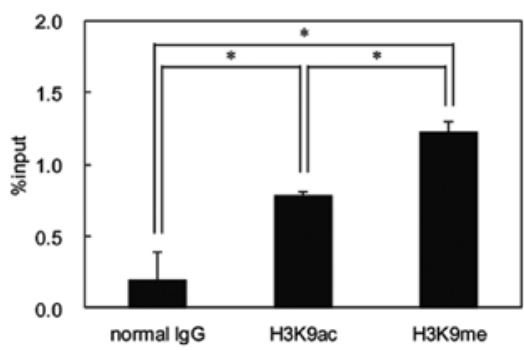

HSC-2

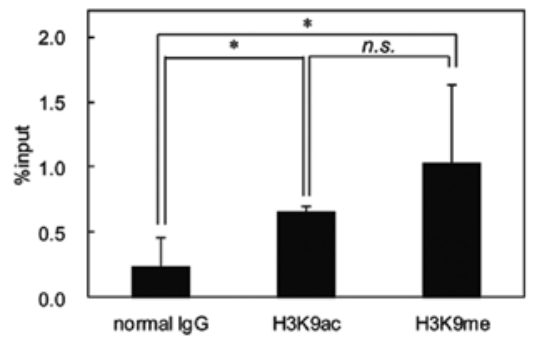

HSC-4

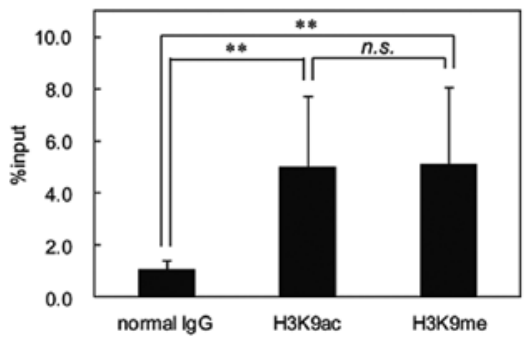

$\mathrm{HO}-1-\mathrm{N}-1$

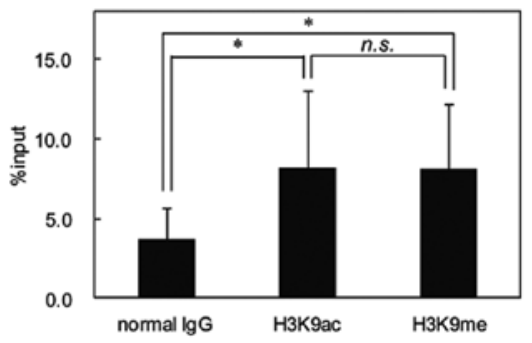

Ca9-22

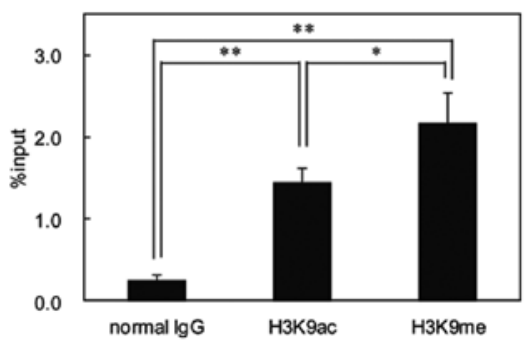

Figure 7. After immunoprecipitation of cross-linked chromatin with acetyl histone $\mathrm{H} 3$ at lysine 9 (H3K9ac) and monomethyl histone $\mathrm{H} 3$ at lysine 9 (H3K9me) antibodies, the enrichment of specific regions in the immunoprecipitated DNA is analyzed by qRT-PCR and expressed as percentages of the input data. Normal goat IgG is used as a negative control. All cell lines have significantly enriched H3K9ac and H3K9me at the promoter region of the FHL1 in OSCC-derived cell lines $\left(\right.$ P $\mathrm{P}<0.05,{ }^{* *} \mathrm{P}<0.01$, Mann-Whitney $\mathrm{U}$ test).

sion of transcription (44). A HDAC inhibitor also is involved in the expression of several genes. In the present study, after treatment of OSCC-derived cell lines with the HDAC inhibitor, $\mathrm{NaB}$, FHL1 transcription was restored in three of eight cell lines. However, the ChIP assay showed that in OSCC-derived cell lines, there was significantly enriched H3K9ac in the FHL1 promoter region. These findings indicated that FHL1 expression in the OSCC-derived cell lines was controlled by epigenetic silencing of aberrant DNA methylation.
The present study suggests that downregulation of FHL1 expression in OSCC-derived cell lines is correlated with $\mathrm{CpG}$ hypermethylation of the FHL1 promoter region rather than histone deacetylation or mutation. This agreed with our initial hypothesis that the FHL1 promoter region is hypermethylated in OSCCs. In this context, with accumulating knowledge of the mechanism of inactivation of tumor suppressor genes, abnormal methylation at the promoters of the tumor suppressor genes is another mechanism that suppresses gene activity. 
In conclusion, our results suggested that downregulation of FHL1 during OSCC development and DNA methylation might play a role in gene inactivation. Further studies with more clinical samples will improve our ability to diagnose, prevent and treat this neoplasm.

\section{Acknowledgements}

We thank Ms. Lynda C. Charters for editing this manuscript.

\section{References}

1. Lippman SM, Sudbø J and Hong WK: Oral cancer prevention and the evolution of molecular-targeted drug development. J Clin Oncol 23: 346-356, 2005.

2. Jemal A, Siegel R, Ward E, et al: Cancer statistics, 2008. CA Cancer J Clin 58: 71-96, 2008.

3. Bettendorf O, Piffkò J and Bànkfalvi A: Prognostic and predictive factors in oral squamous cell cancer: important tools for planning individual therapy? Oral Oncol 40: 110-119, 2004.

4. Kademani D: Oral cancer. Mayo Clin Proc 82: 878-887, 2007.

5. Tatsumoto T, Xie X, Blumenthal R, Okamoto I and Miki T: Human ECT2 is an exchange factor for Rho GTPases, phosphorylated in G2/M phases, and involved in cytokinesis. J Cell Biol 147: 921-928, 1999.

6. Shinozuka K, Uzawa K, Fushimi K, et al: Downregulation of carcinoembryonic antigen-related cell adhesion molecule 1 in oral squamous cell carcinoma: correlation with tumor progression and poor prognosis. Oncology 76: 387-397, 2009.

7. Brown S, McGrath MJ, Ooms LM, Gurung R, Maimone MM and Mitchell CA: Characterization of two isoforms of the skeletal muscle LIM protein 1, SLIM1. Localization of SLIM1 at focal adhesions and the isoform slimmer in the nucleus of myoblasts and cytoplasm of myotubes suggests distinct roles in the cytoskeleton and in nuclear-cytoplasmic communication. J Biol Chem 274: 27083-27091, 1999.

8. McGrath MJ, Mitchell CA, Coghill ID, Robinson PA and Brown S: Skeletal muscle LIM protein 1 (SLIM1/FHL1) induces alpha 5 beta 1-integrin-dependent myocyte elongation. Am J Physiol Cell Physiol 285: C1513-C1526, 2003.

9. Loughna PT, Mason P, Bayol S and Brownson C: The LIM-domain protein FHL1 (SLIM 1) exhibits functional regulation in skeletal muscle. Mol Cell Biol Res Commun 3: 136-140, 2000.

10. Chen DH, Raskind WH, Parson WW, et al: A novel mutation in FHL1 in a family with X-linked scapuloperoneal myopathy: phenotypic spectrum and structural study of FHL1 mutations. J Neurol Sci 296: 22-29, 2010.

11. Oku N, Sasabe E, Ueta E, Yamamoto T and Osaki T: Tight junction protein claudin-1 enhances the invasive activity of oral squamous cell carcinoma cells by promoting cleavage of laminin-5 gamma2 chain via matrix metalloproteinase (MMP)-2 and membrane-type MMP-1. Cancer Res 66: 5251-5257, 2006.

12. Sakashita K, Mimori K, Tanaka F, et al: Clinical significance of loss of Fhl1 expression in human gastric cancer. Ann Surg Oncol 15: 2293-2300, 2008.

13. Fackler MJ, McVeigh M, Mehrotra J, et al: Quantitative multiplex methylation-specific PCR assay for the detection of promoter hypermethylation in multiple genes in breast cancer. Cancer Res 64: 4442-4452, 2004.

14. Fuks F: DNA methylation and histone modifications: teaming up to silence genes. Curr Opin Genet Dev 15: 490-495, 2005.

15. Hassig CA and Schreiber SL: Nuclear histone acetylases and deacetylases and transcriptional regulation: HATs off to HDACs. Curr Opin Chem Biol 1: 300-308, 1997.

16. Huang L: Targeting histone deacetylases for the treatment of cancer and inflammatory diseases. J Cell Physiol 209: 611-616, 2006.

17. Endo Y, Uzawa K, Mochida Y, et al: Sarcoendoplasmic reticulum $\mathrm{Ca}(2+)$ ATPase type 2 downregulated in human oral squamous cell carcinoma. Int J Cancer 110: 225-231, 2004

18. Shimada K, Uzawa K, Kato M, et al: Aberrant expression of RAB1A in human tongue cancer. Br J Cancer 92: 1915-1921, 2005.

19. Saito K, Uzawa K, Endo Y, et al: Plasma membrane $\mathrm{Ca}^{2+}$ ATPase isoform 1 down-regulated in human oral cancer. Oncol Rep 15: $49-55,2006$
20. Kasamatsu A, Uzawa K, Nakashima D, et al: Galectin-9 as a regulator of cellular adhesion in human oral squamous cell carcinoma cell lines. Int J Mol Med 16: 269-273, 2005.

21. Sakuma K, Kasamatsu A, Yamatoji M, et al: Expression status of Zic family member 2 as a prognostic marker for oral squamous cell carcinoma. J Cancer Res Clin Oncol 136: 553-559, 2010.

22. Tanaka C, Uzawa K, Shibahara T, Yokoe H, Noma H and Tanzawa H: Expression of an inhibitor of apoptosis, survivin, in oral carcinogenesis. J Dent Res 82: 607-611, 2003.

23. Kouzu Y, Uzawa K, Kato M, et al: WISP-2 expression in human salivary gland tumors. Int J Mol Med 17: 567-573, 2006.

24. Onda T, Uzawa K, Endo Y, et al: Ubiquitous mitochondrial creatine kinase downregulated in oral squamous cell carcinoma. Br J Cancer 94: 698-709, 2006.

25. Sakuma T, Uzawa K, Onda T, et al: Aberrant expression of histone deacetylase 6 in oral squamous cell carcinoma. Int J Oncol 29: 117-124, 2006.

26. Kato Y, Uzawa K, Yamamoto N, et al: Overexpression of Septin1: possible contribution to the development of oral cancer. Int J Oncol 31: 1021-1028, 2007.

27. Nomura H, Uzawa K, Yamano Y, et al: Overexpression and altered subcellular localization of autophagy-related 16-like 1 in human oral squamous-cell carcinoma: correlation with lymphovascular invasion and lymph-node metastasis. Hum Pathol 40: 83-91, 2009.

28. Iyoda M, Kasamatsu A, Ishigami T, et al: Epithelial cell transforming sequence 2 in human oral cancer. PloS One 5: e14082, 2010.

29. Yamatoji M, Kasamatsu A, Kouzu Y, et al: Dermatopontin: a potential predictor for metastasis of human oral cancer. Int $\mathrm{J}$ Cancer 130: 2903-2911, 2012.

30. Lombardi DP, Geradts J, Foley JF, Chiao C, Lamb PW and Barrett JC: Loss of KAIl expression in the progression of colorectal cancer. Cancer Res 59: 5724-5731, 1999.

31. Verburg FA, Wäschle K, Reiners C, Giovanella L and Lentjes EG: Heterophile antibodies rarely influence the measurement of thyroglobulin and thyroglobulin antibodies in differentiated thyroid cancer patients. Horm Metab Res 42: 736-739, 2010.

32. Li LC and Dahiya R: MethPrimer: designing primers for methylation PCRs. Bioinformatics 18: 1427-1431, 2002.

33. Van der Auwera I, Van Laere SJ, Van den Bosch SM, et al: Aberrant methylation of the adenomatous polyposis coli (APC) gene promoter is associated with the inflammatory breast cancer phenotype. Br J Cancer 99: 1735-1742, 2008.

34. Kimura H,Hayashi-Takanaka Y, Goto Y, Takizawa N and Nozaki N: The organization of histone $\mathrm{H} 3$ modifications as revealed by a of specific monoclonal antibodies. Cell Struct Funct 33: 61-73, 2008.

35. Wang LL, Qiu GR, Fu WN, Yuan ZW and Sun KL: Transcriptional regulation of Fhl1 by estradiol in rat myoblastocytes. Steroids 75: 368-372, 2010.

36. Shen Y, Jia Z, Nagele RG, Ichikawa $H$ and Goldberg GS: SRC uses Cas to suppress Fhl1 in order to promote nonanchored growth and migration of tumor cells. Cancer Res 66: 1543-1552, 2006.

37. Fryknas M, Wickenberg-Bolin U, Goransson H, et al: Molecular markers for discrimination of benign and malignant follicular thyroid tumors. Tumour Biol 27: 211-220, 2006.

38. Li X, Jia Z, Shen Y, et al: Coordinate suppression of Sdpr and Fhl1 expression in tumors of the breast, kidney, and prostate. Cancer Sci 99: 1326-1333, 2008.

39. Yuan J, Luo RZ, Fujii S, et al: Aberrant methylation and silencing of ARHI, an imprinted tumor suppressor gene in which the function is lost in breast cancers. Cancer Res 63: 4174-4180, 2003.

40. Chen K, Sawhney R, Khan M, et al: Methylation of multiple genes as diagnostic and therapeutic markers in primary head and neck squamous cell carcinoma. Arch Otolaryngol Head Neck Surg 133: 1131-1138, 2007.

41. Henken FE, Wilting SM, Overmeer RM, et al: Sequential gene promoter methylation during HPV-induced cervical carcinogenesis. Br J Cancer 97: 1457-1464, 2007.

42. Magdinier F and Wolffe AP: Selective association of the methylCpG binding protein MBD2 with the silent p14/p16 locus in human neoplasia. Proc Natl Acad Sci USA 98: 4990-4995, 2001.

43. Cheung P and Lau P: Epigenetic regulation by histone methylation and histone variants. Mol Endocrinol 19: 563-573, 2005.

44. Hong S, Derfoul A, Pereira-Mouries L and Hall DJ: A novel domain in histone deacetylase 1 and 2 mediates repression of cartilagespecific genes in human chondrocytes. FASEB J 23: 3539-3552, 2009. 